\title{
Cellular Immune Response Involving Multinucleated Giant Hemocytes with Two-Step Genome Amplification in the Drosophilid Zaprionus indianus
}

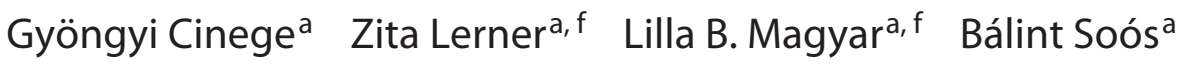 \\ Renáta Tóth $^{a}$ Ildikó Kristób $^{b}$ Péter Vilmos $^{b}$ Gábor Juhász $^{c}$ Attila L. Kovács ${ }^{c}$ \\ Zoltán Hegedűs $^{d}$ Christoph W. Sensen ${ }^{e}$ Éva Kurucz ${ }^{a}$ István Andóa \\ almmunology Unit, Institute of Genetics, Biological Research Centre, Hungarian Academy of Sciences, Szeged, \\ Hungary; ${ }^{b}$ Developmental Genetics Unit, Institute of Genetics, Biological Research Centre, Hungarian Academy of \\ Sciences, Szeged, Hungary; ' Department of Anatomy, Cell and Developmental Biology, Eötvös Loránd University, \\ Budapest, Hungary; ${ }^{d}$ Laboratory of Bioinformatics, Biological Research Centre, Hungarian Academy of Sciences, \\ Szeged, Hungary; ${ }^{\mathrm{e}}$ Institute of Computational Biotechnology, Graz University of Technology, Graz, Austria; ${ }^{\mathrm{f} D o c t o r a l}$ \\ School of Biology, University of Szeged, Szeged, Hungary
}

\section{Keywords}

Zaprionus indianus · Hemocyte $\cdot$ Multinucleated .

Encapsulation · Drosophila · Host defense · Parasitology ·

Immunity · Granuloma

\begin{abstract}
Previously, a novel cell type, the multinucleated giant hemocyte (MGH) was identified in the ananassae subgroup of Drosophilidae. These cells share several features with mammalian multinucleated giant cells, a syncytium of macrophages formed during granulomatous inflammation. We were able to show that MGHs also differentiate in Zaprionus indianus, an invasive species belonging to the vittiger subgroup of the family, highly resistant to a large number of parasitoid wasp species. We have classified the MGHs of $Z$. indianus as giant hemocytes belonging to a class of cells which also include elongated blood cells carrying a single nucleus and anuclear
\end{abstract}

\section{KARGER}

E-Mail karger@karger.com www.karger.com/jin

\section{(C) 2019 The Author(s)}

Published by S. Karger AG, Basel

Karger

Open access

This article is licensed under the Creative Commons AttributionNonCommercial-NoDerivatives 4.0 International License (CC BY NC-ND) (http://www.karger.com/Services/OpenAccessLicense). Usage and distribution for commercial purposes as well as any distribution of modified material requires written permission. structures. They are involved in encapsulating parasites, originate from the lymph gland, can develop by cell fusion, and generally carry many nuclei, while possessing an elaborated system of canals and sinuses, resulting in a spongiform appearance. Their nuclei are all transcriptionally active and show accretion of genetic material. Multinucleation and accumulation of the genetic material in the giant hemocytes represents a two-stage amplification of the genome, while their spongy ultrastructure substantially increases the contact surface with the extracellular space. These features may furnish the giant hemocytes with a considerable metabolic advantage, hence contributing to the mechanism of the effective immune response.

(C) 2019 The Author(s)

Published by S. Karger AG, Basel

Gyöngyi Cinege and Zita Lerner contributed equally to this work.
Dr. István Andó

Immunology Unit, Institute of Genetics

Biological Research Centre, Hungarian Academy of Sciences

Temesvári Krt. 62, HU-6726 Szeged (Hungary)

E-Mail ando@brc.hu 


\section{Introduction}

Multicellular organisms are confronted with a wide array of infective microorganisms and parasites. In order to defend against these invaders and maintain homeostasis, they have evolved diverse inborn defense mechanisms, such as the external mechanical barriers and the immune system, respectively. The phylogenetically oldest component of the immune system is the innate immunity, which develops in spatially and temporally distinct phases of hematopoietic development, with similarities between insects and vertebrates [1]. Innate immunity constitutes the first line of immune defense, protecting the organism from microbes and parasites and synergizing with the adaptive immunity in vertebrates. The key components of innate immunity, including transcriptional and epigenetic regulators and signal transduction pathways, are phylogenetically conserved $[2,3]$. Due to the available genetic, genomic, and immunological tools, Drosophila melanogaster has become one of the predominant model organisms for studies of fundamental mechanisms of innate immunity and host-pathogen interaction.

The cellular immune response of $D$. melanogaster involves three types of blood cells, collectively called hemocytes [4], which are organized in three anatomical compartments: the circulation, the sessile tissue, and the lymph gland [5-7]. Plasmatocytes, representing the major hemocyte class, are small spherical cells, which produce antimicrobial peptides, extracellular matrix proteins, which can engulf and ingest prokaryotes. The crystal cells are similar in their morphology to plasmatocytes but contain phenoloxidases in the form of cytoplasmic inclusions, which are required for melanization reactions. The plasmatocytes and crystal cells are present and ready to act immediately upon infection or injury in the larva and the adult. The third cell type, i.e. the lamellocytes, differentiate from plasmatocytes in the circulation and the sessile tissue or from progenitors of the hematopoietic organ, the lymph gland, after parasitic infection or wounding the larva $[4,6,8-17]$. They are involved in the encapsulation reaction by enveloping, isolating, and melanizing large particles, like eggs or the larvae of parasitoids. Lamellocytes have been described in several Drosophila species, belonging to the melanogaster subgroup of Drosophilidae [18-20]; however, recently morphological and functional variations have been revealed among capsule-forming cells of different dipteran species. In D. affinis and D. obscura phagocytic and capsule-forming pseudopodocytes have been described [21].
We have previously identified a novel cell type in Drosophila innate immunity, the multinucleated giant hemocyte (MGH), in several species of the ananassae subgroup of Drosophilidae [22]. MGHs are non-proliferative effector cells, which are derived from phagocytic plasmatocytes. They are gigantic syncytia of hemocytes with filamentous projections, containing many nuclei, able to envelope and kill parasitic wasps with high efficiency without apparent melanotic reaction. The capsule formation in response to parasitoid infection serves as a viable model for foreign body-type granulomas in vertebrates, a typical reaction to chronic inflammatory stimuli [23]. Recently, we have found that MGHs can also develop in $\mathrm{Za}$ prionus indianus, a species belonging to the vittiger subgroup of the Drosophilidae, where previously nematocytes, lamellocytes, podocytes, and plasmatocytes had already been identified [20]. This species uses both melanotic and non-melanotic encapsulation when protecting the organism from the parasitoid wasps, and it is highly resistant to a large number of wasp species [20]. As $\mathrm{Za}$ prionus indianus uses a large variety of fruits and vegetables as sites for oviposition, it can cause extensive economic damage [24]. While the species was originally prevalent in the Oriental region and Africa [25], it appeared in Brazil in 1999 [26], spreading rapidly throughout all of South America, as well as parts of the North American continent [27]. Recently, it was found in France [28], and it is therefore expected that within a short period of time it could cause economic problems in Europe as well [29]. Therefore, it is of great interest to learn about the biology and the immune defense mechanisms of this species, with special emphasis on the MGHs.

In order to gain insights into the basis of the cellular immunity of $Z$. indianus, we carried out a functional and developmental analysis of the hemocyte subsets and the immune compartments, using a newly developed antibody-based system, complementing the studies with transmission electron microscopy. We have revealed unique features of the cell-mediated immunity of this species, which provide clues towards the understanding of the immune response accomplished by MGHs.

\section{Materials and Methods}

Insect Stocks and Culturing

$Z$. indianus strain \#1 and strain \#3 [20] were kindly provided by Bálint Z. Kacsoh (University of Pennsylvania, USA). Stocks were kept at $25^{\circ} \mathrm{C}$ on standard yeast-cornmeal food. The experiments were done with both strains. As the antigen manifestation and all tested parameters were the same in the two stocks, the re- 
sults obtained with strain \#3 are presented. The Leptopilina victoriae wasp strain LvUNK was kindly provided by Prof. Todd Schlenke (University of Arizona, USA). Wasps were maintained on D. melanogaster Oregon R.

\section{Monoclonal Antibodies}

The immunization with hemocytes and the production of monoclonal antibodies has been described previously [30]. Hybridoma supernatants were screened with indirect immunofluorescence on immune-induced $Z$. indianus blood cells, isolated $72 \mathrm{~h}$ after wasp infection. (The antibodies are freely available on request from I.A.) The molecular mass of the hemocyte antigens, which are recognized by the antibodies was determined by Western blot [30] and is shown in online supplementary Figure S1 (see www.karger.com/doi/10.159/000502646 for all online suppl. material). The 12F6 antibody (a generous gift from Prof. Tina Trenczek, Giessen University, Germany) was used to detect crystal cells. The $4 \mathrm{G} 7$ and 5C3 antibodies are $Z$. indianus specific. The $12 \mathrm{~F} 6$ antibody was generated originally to Hyalophora cecropia hemocytes, and cross-reacts with the crystal cells of D. melanogaster, Manduca sexta $[31,32]$ and Z. indianus blood cells. In D. melanogaster, this antibody reacts with the prophenoloxydase PPO2 (79.3 $\mathrm{kDa}$ ) [32], which shows an $88 \%$ homology on a 645 amino acid stretch with a protein encoded by a region of the LWKS01004021.1 Z. indianus strain IND_ZI_P10 Scaffold4157 whole-genome shotgun sequence [29]. As the predicted molecular mass of the PPO2 $Z$. indianus ortholog was $75 \mathrm{kDa}$, corresponding to the band marked by the 12F6 antibody in the Western blot analysis of $Z$. indianus hemocytes (online suppl. Fig. S1), we concluded that the $12 \mathrm{~F} 6$ recognized the PPO2 ortholog in this species.

\section{Hemocyte Isolation and Preparation of the Lymph Gland}

All procedures were carried out at room temperature. Z. indianus larvae were dissected in Schneider's medium (Lonza) supplemented with 5\% fetal bovine serum (GIBCO) and 0.01\% 1-phenyl2-thiourea (Sigma) (CSM) on microscope slides. Blood cells were adhered to glass microscopic slides for $1 \mathrm{~h}$. The $\mathrm{CO}_{2}$-anesthetized 1 -day-old adults were perfused using a glass capillary, containing CSM. Hemocytes of 3 adults were pooled for each sample and used for further analysis. Preparation of the lymph gland was performed as described previously [22].

Antibodies, Indirect Immunofluorescence, and Image Analysis

Hemocytes were fixed with acetone for $6 \mathrm{~min}$, air dried, and blocked with $0.1 \%$ BSA in PBS for $20 \mathrm{~min}$. Cuticle preparations and encapsulated wasp eggs/larvae were fixed with $2 \%$ paraformaldehyde for 10 min and blocked with $0.1 \%$ BSA in PBS supplemented with $0.01 \%$ Triton X-100. The fixed samples were treated identically, as follows. Incubation with the primary antibodies $(5 \mathrm{C} 3$, $4 \mathrm{G} 7,12 \mathrm{~F} 6$, and a negative control monoclonal antibody T2/48 [33] in the form of undiluted hybridoma supernatants) was performed for $1 \mathrm{~h}$. Samples were washed 3 times for $5 \mathrm{~min}$ in PBS, incubated with the secondary antibody and DAPI for $45 \mathrm{~min}$, washed 3 times with PBS for 5 min and covered with Fluoromount G medium and coverslip. The samples were analyzed with an epifluorescence microscope (Zeiss Axioscope 2 MOT), with an Olympus FV1000 confocal LSM microscope or with a Leica TCS SP5 confocal microscope, respectively. The anti-phospho-histoneH3 was a rabbit polyclonal antibody (Sigma, 1:1,000 dilution). The antibody to the active form of RNA polymerase was anti-RNA polymerase II CTD (phospho S2) rabbit antibody (Abcam, 1:100 dilution). Secondary antibodies were anti-mouse CF 568 goat antibody (Biotium, 1: 1,000 dilution), anti-mouse Alexa Fluor 488 goat antibody (Invitrogen, 1:1,000 dilution), and anti-rabbit Alexa Fluor 488 goat antibody (Invitrogen, 1:1,000 dilution). Actin staining was carried out with Phalloidin-AttoRho6G (Sigma, 1:500 dilution). Olympus Fluoview and Olympus 3D viewer software were used to prepare the $3 \mathrm{D}$ animation of phalloidin and DAPI-stained MGH, using $\times 60$ oil immersion objective and 29 optical sections with 4 frame/s rate.

Visualization of the Crystal Cells in situ Using Heat Treatment In D. melanogaster, crystal cells melanize when larvae are incubated at $60^{\circ} \mathrm{C}$ for $10 \mathrm{~min}$ [34]. We have optimized the protocol for $Z$. indianus larvae with heat treatment for $40 \mathrm{~min}$. Therefore, crystal cells were quantified by counting dark spots in incubated whole larvae at 24,48 , and $72 \mathrm{~h}$ post-infection of 24 larvae per sample in three independent experiments.

\section{BrdU Labeling of the Larvae and ex vivo Detection of Cell}

Fusion

BrdU (bromodeoxy-uridine) labelling of cell nuclei was carried out as described previously [22]. Antimitotic treatment was carried out for the BrdU-labeled and control larvae. The larvae were fed $2 \mathrm{~h}$ before cell fusion analysis with standard yeast-cornmeal food containing $1 \mathrm{mg} / \mathrm{mL}$ aphidicoline (Sigma-Aldrich, A0781) [35]. Following the treatment, ex vivo detection of cell fusion was examined as described previously [22].

\section{Cell, Nuclear, and Fluorescence Intensity Measurements}

Cellular sizes, nuclear sizes, and fluorescence intensity of the nuclei were determined with the ImageJ program (http://imagej. nih.gov/ij/). The size of the hemocytes was measured in three independent experiments, with 30 larvae each. Nuclear size and fluorescence intensity measurements were performed in three independent experiments, 12 samples each. The significance of the differences was determined by using Student's $t$ test or Mann-Whitney $\mathrm{U}$ test. The differences with a $p$ value $<0.05$ were considered as significant.

\section{Videomicroscopy}

Two larvae were dissected in $100 \mu \mathrm{L}$ CSM, $72 \mathrm{~h}$ after L. victoriae wasp infection. The live hemocytes were analyzed with an $\mathrm{Al}$ pha XDS-1T inverse microscope at room temperature. Photographs were taken with a Nikon D5300 DSLR camera. Shooting duration was 150 min with 95-s intervals (online suppl. movie 1) or 60 min with 12-s intervals (online suppl. Movies 2 and 3). The images were edited with the Adobe Lightroom CC 2015 program, and the movie was made with FIJI (https://fiji.sc/).

\section{In vitro and in vivo Phagocytosis Assay}

For the phagocytosis assay, FITC-labeled Escherichia coli cells (SzMC 0582) (Szeged Microbial Collection, University of Szeged, Hungary) $(50 \mu \mathrm{L}$ pelleted bacteria in $450 \mu \mathrm{L}$ PBS) (E. coli-FITC) were used. For in vitro phagocytosis, assay hemocytes were isolated on microscopic slides in $100 \mu \mathrm{L} \mathrm{CSM}$, and $5.7 \mu \mathrm{L}$ E. coli-FITC was added to the blood cells and incubated for $45 \mathrm{~min}$ at room temperature. The fluorescence of the non-phagocytosed bacteria was quenched with trypan blue ( $0.2 \%$ final concentration), and the fluorescence of the engulfed bacteria was visualized with an epi- 
fluorescence microscope (Zeiss Axioscope 2 MOT). The in vivo phagocytosis assay was carried out by injecting larvae $72 \mathrm{~h}$ after infection with $0.1 \mu \mathrm{L}$ E. coli-FITC. Hemocytes were isolated $1 \mathrm{~h}$ after injection, fixed and reacted with the respective antibodies as described above. Analysis was performed with an Olympus FV1000 confocal LSM microscope, and images in the nucleus plane were used. The phagocytic capacity of the hemocytes was correlated with their immunological phenotype.

\section{Isolation of Cell Nuclei from Larval Hemocytes, DAPI Staining,} and FACS Analysis

Cells of naïve and L. victoriae-infected ( $72 \mathrm{~h}$ after infection) larvae were isolated in CSM, pelleted by centrifugation, and washed twice with ice-cold PBS, resuspended in harvest buffer $(10 \mathrm{mM}$ HEPES pH 7.9, $50 \mathrm{mM} \mathrm{NaCl}, 0.5 \mathrm{M}$ sucrose, $0.1 \mathrm{~mm}$ EDTA, $0.5 \%$ Triton X-100), containing Complete Protease Inhibitor Cocktail (Roche). The cells were incubated on ice for $5 \mathrm{~min}$, and subsequently centrifuged for $10 \mathrm{~min}$ with $800 \mathrm{~g}$ at $4{ }^{\circ} \mathrm{C}$. The supernatant was discarded and the nuclei were resuspended in Buffer A $(10 \mathrm{mM}$ HEPES pH 7.9, 10 mM KCl, 0.1 mM EDTA, 0.1 mM EGTA) (Sigma) and Complete Protease Inhibitor Cocktail (Roche), supplemented with $50 \mu \mathrm{g} / \mathrm{mL}$ RNAse A (Sigma), incubated for $30 \mathrm{~min}$ at $37^{\circ} \mathrm{C}$, and then centrifuged for $10 \mathrm{~min}$ with $800 \mathrm{~g}$ at $4^{\circ} \mathrm{C}$. The supernatant was discarded, and the pellet was resuspended in ice-cold Buffer A. The nuclei were stained with DAPI $(0.4 \mu \mathrm{g} / \mathrm{mL})$ and the size and the fluorescence intensity of the gated nuclei was determined with a BD FACSJazz Cell Sorter.

\section{Electron Microscopy}

Fixation was carried out for $48 \mathrm{~h}$ in a 1:1 mixture of the following two solutions in distilled water: $6.4 \%$ formaldehyde (Polysciences), $1 \%$ glutaraldehyde (EM Grade, Polysciences), $4 \mathrm{~mm}$ $\mathrm{CaCl}_{2}$ (Molar Chemicals), $2 \%$ sucrose (Molar Chemicals), $0.1 \mathrm{M} \mathrm{Na}$ cacodylate (Sigma) as one part, and $4 \%$ tannic acid (Sigma), $0.1 \mathrm{M}$ $\mathrm{Na}$ cacodylate as the other part, final pH 7.4. Washing in cacodylate ( $\mathrm{pH} 7.4$ ) was followed by staining en block in $2 \%$ uranyl acetate (EM, Taab Laboratory and Microscopy) dissolved in distilled water. The embedding procedure included dehydration in a graded series of ethanol $(50,70$, two times 96 , and $100 \%)$, then in propylene oxid (Sigma); infiltration in propylene oxid: Durcupan ACM (Sigma) epoxy resin 2:1, overnight in propylene oxid: Durcupan 1: 2 , and Durcupan; polymerization took place for $48 \mathrm{~h}$ at $60^{\circ} \mathrm{C}$. To observe the samples in the electron microscope, $90-\mathrm{nm}$ sections were created using a Reichert Ultracut ultramicrotome and stained in Reynold's lead citrate [36]. Sections were viewed in a JEM-1011 JEOL transmission electron microscope, and pictures taken with a Morada, Olympus camera and iTEM software (Olympus).

\section{Results}

\section{Heterogeneity of Z. indianus Hemocytes as Revealed by Discriminative Monoclonal Antibodies}

As studies have previously shown that there are several molecular patterns presented on hemocytes, which can be used to distinguish their functional subsets [30], we produced and used discriminative monoclonal anti- bodies to stain $Z$. indianus hemocytes to uncover their heterogeneity. On the basis of the reaction pattern, three main hemocyte types could be distinguished under naïve and infected conditions, both in the larva and in the adult (Fig. 1). In the naïve larva, the $4 \mathrm{G} 7$ antibody reacted with the giant hemocytes, including MGHs carrying more than one nucleus, with nematocytes, elongated blood cells carrying a single nucleus, and anucleated structures (Fig. 1a), and was unreactive with plasmatocytes. This reaction pattern suggests that the anucleated structures may originate from the MGHs or from elongated cells carrying a single nucleus. The $5 \mathrm{C} 3$ antibody reacted with the plasmatocytes which are spherical cells of different sizes (Fig. 1b) and the 12F6 antibody reacted with a minor population of spherical cells apparently corresponding to the crystal cells (Fig. 1c).

The wasp infection resulted in changes in the composition of the circulating blood cell population: the total hemocyte count slightly but not significantly $(p>0.5)$ increased (Fig. 2a); however, the proportion and size of the MGHs (4G7-positive cells) increased (online suppl. Fig. S2, Fig. 1d); furthermore, the nuclei of the 4G7-positive cells enlarged (Fig. 1d). Also, large plasmatocytes (5C3positive spherical cells) differentiated (Fig. 1e). As shown in online supplementary Figure S2, $72 \mathrm{~h}$ after wasp infection $24.5 \%$ of the $5 \mathrm{C} 3$-positive cells fell into the large plasmatocyte fraction, and these cells occasionally had enlarged nuclei or even more than one nucleus (Fig. 1e). Furthermore, $8.8 \%$ of the crystal cells increased in their size in wasp-infected larvae when comparing to the area of the crystal cells in the naïve samples (online suppl. Fig. S2). A threefold increase in the number of the crystal cells was observed in the hemolymph (Fig. 2a).

We have also carried out heat treatment of the larvae to visualize the crystal cells in situ after heat treatment for time points 24,48 , and $72 \mathrm{~h}$ after the wasp infection. At each time point, significantly more crystal cells were observed in L. victoriae-infected larvae $(p<0.001)$. The $72 \mathrm{~h}$ reactions are presented in Figure $2 b$.

We have also analyzed the blood cells of 1-day-old adults, which developed from naïve and L. victoriae-parasitized larvae, respectively. The number of the hemocytes in the adults was approximately $5 \%$ of that of the third-instar larvae. Filariform, 4G7-positive (Fig. 1g, j), spherical 5C3-positive (Fig. 1h, k), and 12F6-positive cells (Fig. 1i, l) and 4G7-positive anucleated structures were all present in the hemolymph. Interestingly, in the 4G7 population only mononuclear multiform cells and anucleated structures were detected. The hemocyte count, the proportion of the subsets, and the morphological features 


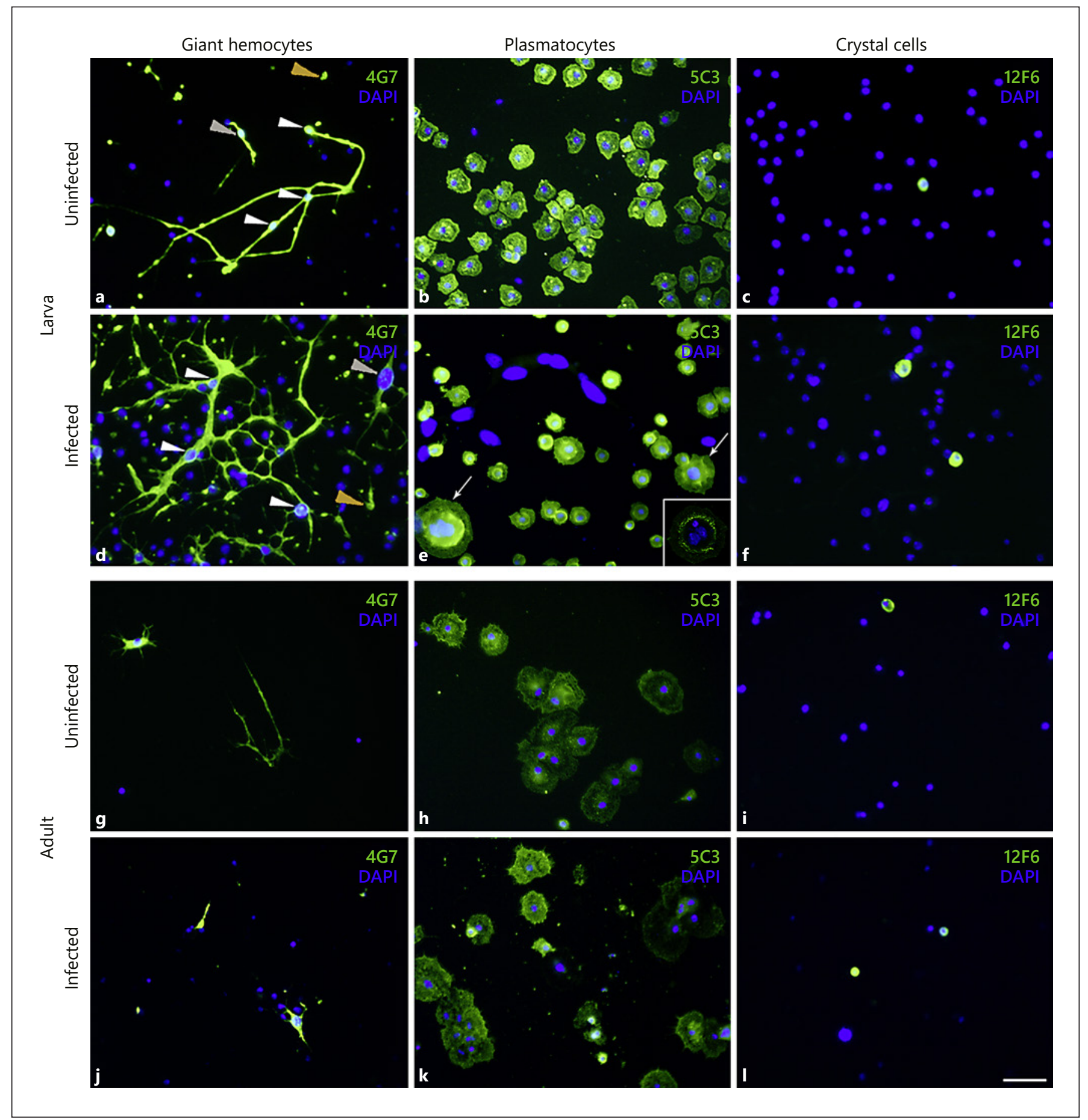

Fig. 1. Characterization of $Z$. indianus hemocytes using monoclonal antibodies. Hemocytes of uninfected and infected larvae and adults (infected adults were developed from wasp-infected larvae) were reacted with cell type-specific monoclonal and secondary, anti-mouse Alexa Fluor 488 antibodies. Cell nuclei were visualized with DAPI. a, d The MGHs (white arrowheads point to nuclei), the nematocytes (gray arrowheads), and the anucleated structures (brown arrowheads) are marked. e Arrows point to large spherical cells of the infected larvae; the insert shows merge of four confocal layers in a large plasmatocyte with multiple nuclei. g-I Hemocytes of three adults were pooled for each sample. Staining was analyzed with an epifluorescence Zeiss Axioscope 2 MOT microscope (a-i) or with an Olympus FV1000 confocal LSM microscope (for insert of e). The scale bar represents $20 \mu \mathrm{m}$.
Genome Amplification during the Cellular Immune Response of Drosophila
J Innate Immun 2020;12:257-272 DOI: $10.1159 / 000502646$ 
Fig. 2. Total hemocyte and crystal cell counts $72 \mathrm{~h}$ following the immune induction with $L$. victoriae. a Analysis of total hemocyte and crystal cell number in the hemolymph of uninfected and wasp-infected larvae. Crystal cells were identified based on 12F6 positivity. Blood cells were counted with the ImageJ program (http://imagej. nih.gov/ij/). Four independent experiments were done, each with 10 larvae. b Crystal cells in heat-treated larvae. Waspinfected and uninfected larvae were treated for $40 \mathrm{~min}$ at $60^{\circ} \mathrm{C}$ to reveal melanized crystal cells. Three independent experiments were done, at each time point with 72 larvae. The error bars indicate the standard error of the mean. Level of significance was determined with the MannWhitney U test, ${ }^{*} p<0.001$.

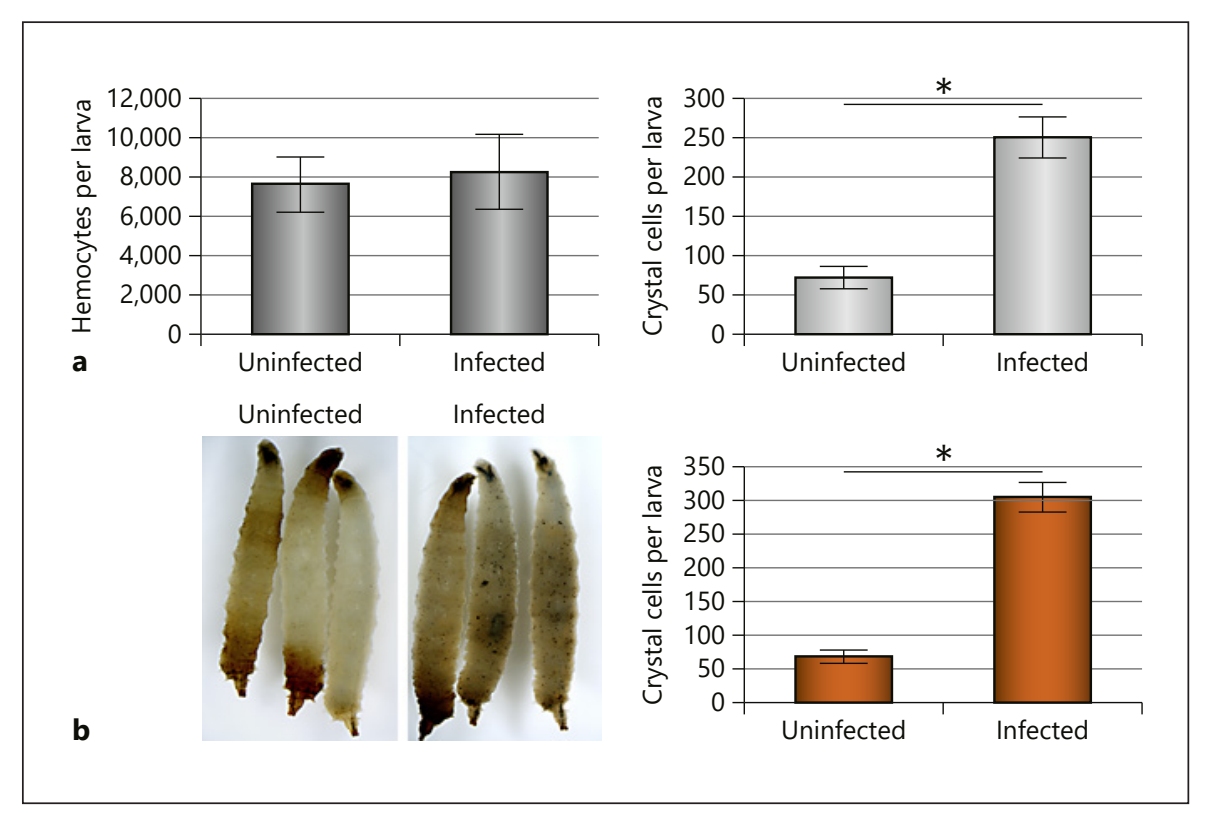

of the cells were the same in the adults, regardless of whether they developed from infected or naïve larvae, respectively (data not shown).

\section{Mechanism of MGH Formation and Transcriptional Activity of the Nuclei}

As in D. ananassae syncytium formation and multinucleation of hemocytes can occur by cell fusion [22], we investigated whether this process could contribute to formation of MGHs in $Z$. indianus as well. Actin-microtubule staining of hemocytes with phalloidin showed continuous labeling of interconnecting cytoplasmic bundles, without separating plasma membrane between the nuclei (Fig. 3a) implying that the nuclei are not separated from each other. Moreover, a 3D confocal picture reconstruction of a phalloidin and DAPI-stained MGH showed that the nuclei were located in the same cytoplasm (online suppl. Movie 4). To verify that multinucleation can be the result of cell fusion, the nucleotide analogue BrdU was used to label the DNA of hemocytes. Seventy-two hours after infection with L. victoriae, blood cells of BrdU-treated $Z$. indianus larvae were isolated and mixed ex vivo with unlabeled hemocytes from infected larvae. As shown in Figure 3d, both BrdU-labeled and unlabeled nuclei were present in the same cytoplasm, confirming that cell fusion can contribute to MGH formation. Moreover, we tested whether or not mitosis might also have role in MGH formation. At different time points following the infection with $L$. victoriae, we tested the presence of the mitotic marker phospho-histone $\mathrm{H} 3(\mathrm{H} 3 \mathrm{P})$ in the circulating 4G7-positive giant cells. Indirect immunofluorescence analysis, using anti-H3P antibody, revealed that in the circulation the fraction of $\mathrm{H} 3 \mathrm{P}$-positive cells was the largest $(0.2 \%)$ at $48 \mathrm{~h}$ after infection. More than 430,000 cells were scored for $\mathrm{H} 3 \mathrm{P}$ expression, and the signal appeared in the plasmatocytes but was not seen in giant cells (data not shown).

Previously, it was shown that in multinucleated osteoclasts the level of transcriptional activity varies between nuclei [37]; therefore, we investigated if all nuclei were transcriptionally active in the multinucleated giant cells of infected larvae, by using an antibody recognizing the active form of RNA polymerase II, in combination with the 4G7 giant cell marker. We found that all nuclei of MGHs were positive for the active RNA polymerase II staining (online suppl. Fig. S3).

\section{Giant Hemocytes Are Motile, Transform Shape, and} Fuse

Wasp infected larvae were bled on slides and the activity of hemocytes was recorded in a time-lapse movie ex vivo. We showed that the giant cells were strikingly motile, moved vigorously (online suppl. Movies), fused (online suppl. Movies 1 and 3), changed shape, and projected filariform extensions. Spherical cells could also change shape and also took on elongated forms (see online suppl. Movies 1 and 2). 
Functional Characteristics of the Hemocyte Subsets

We analyzed the role of the three main blood cell populations in the phagocytosis of microbes and the encapsulation reaction. The phagocytic capacity of the hemocytes of naïve and L. victoriae-infected third-instar larvae was tested using FITC-labeled Escherichia coli bacteria. The bacteria were taken up by both small and large 5C3positive spherical cells, the plasmatocytes; however, the 4G7-positive giant cells and anucleated structures never engulfed bacteria (Fig. 4). Time-lapse encapsulation experiments, using immunostaining with the discriminative antibodies, revealed that the 5C3-, as well as the 4G7positive cells contributed to the formation of the capsule (Fig. 5). The 5C3-positive cells, the plasmatocytes, were found on the egg at each time point, while the 4G7-positive cells were present in low numbers on the parasite at $24 \mathrm{~h}$, and their presence gradually increased and peaked at $72 \mathrm{~h}$. With 12F6, the crystal cell-specific antibody, we observed a diffuse signal, which was most intense $72 \mathrm{~h}$ after infection.

\section{Compartmental Origin of the MGHs}

It has been established that in D. melanogaster the lamellocytes develop after immune induction [9], and all three hematopoietic compartments contribute to the anti-parasite response $[6,14]$. As we observed giant hemocytes in naïve $Z$. indianus animals, we determined roles of the hematopoietic compartments in giant cell differentiation both in naïve and parasitized larvae.

Cells carrying the 4G7 antigen were present in the lymph gland and in the circulation in all larval developmental stages in naïve and infected state (Fig. 6); moreover, these cells were detected in the sessile tissue too (online suppl. Fig. S4). Parasitoid wasp infection caused dramatic changes in the structure of the lymph gland. When compared to the control (Fig. 6c), the organ was swollen (Fig. 6d), the proportion of the 4G7-positive cells was increased, and $72 \mathrm{~h}$ after infection the primary lobes started to disintegrate. Moreover, at the posterior part of the dorsal vessel, around the pericardial cells, 4G7-positive cells accumulated (Fig. 6i, j) both in naïve and in infected larvae.

In order to analyze the possible role of the lymph gland in multinucleation, we examined the organ for the presence of the H3P mitotic cell marker. The mitotic cells were present at the highest proportion $24 \mathrm{~h}$ after wasp infection, on average with $22 \mathrm{H} 3 \mathrm{P}$-positive cells per organ. The H3P marker could also be detected in the nuclei of some 4G7-positive cells (Fig. 7a). On average, $9 \mathrm{H} 3 \mathrm{P}$ positive cells were observed in the lymph glands of unin-
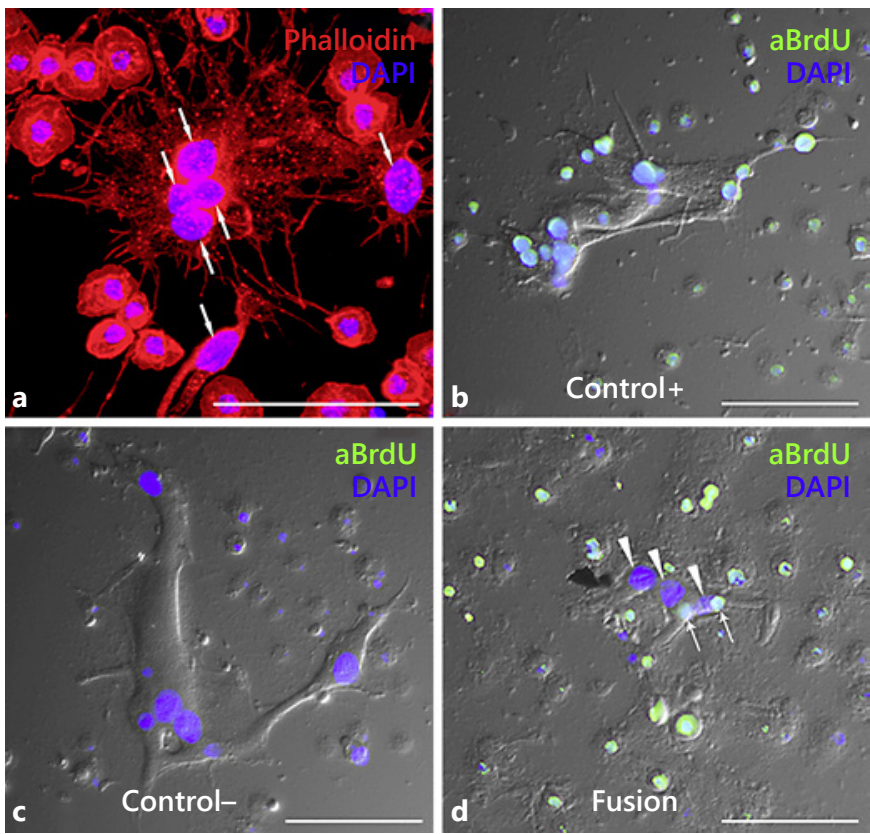

Fig. 3. Syncytium formation and multinucleation occurs by cell fusion. a Phalloidin-AttoRho6G staining of hemocytes from immune-induced Z. indianus larvae. Arrows point to the nuclei of the multinucleated giant hemocyte. BrdU-labeled (b) and unlabeled (c) larvae, $72 \mathrm{~h}$ after the wasp infection, were treated with the antimitotic aphidicoline, and their isolated blood cells were mixed in vitro (d) and reacted with mouse anti-BrdU Alexa Fluor 488 antibody (green) and DAPI (blue). d Arrows show BrdU-labeled, while arrowheads point to BrdU-unlabeled nuclei of the fused cell. Detection was done with an Olympus FV1000 confocal LSM microscope (a) and an epifluorescence Zeiss Axioscope 2 MOT microscope (b-d). Scale bars represent $50 \mu \mathrm{m}$.

fected larvae of the same developmental stage. Moreover, we observed that $48 \mathrm{~h}$ after the infection some $4 \mathrm{G} 7$-positive cells had more than one nucleus (Fig. $7 \mathrm{~b}$ ), indicating that multinucleation of the giant cells may already occur in the lymph gland. At this stage, we also detected that all 4G7-positive cells carried enlarged nucleus (Fig. 7b).

\section{Immune Induction Generates Increased Nuclear DNA Content in Hemocytes}

Based on DAPI and immunostaining experiments, we observed that the nuclei of the giant blood cells and part of the large plasmatocytes were enlarged, when compared to those of the majority of plasmatocytes (Fig. 1d, e). To correlate the nuclear size and DNA content, we isolated intact nuclei from naïve and wasp-infected hemocytes, stained the DNA with DAPI; then, the fluorescence intensity and the size of the nuclei were analyzed by flow cy- 
Fig. 4. Phagocytic capacity of the hemocyte subsets. a FITC-labelled E. coli bacteria were incubated with hemocytes isolated from uninfected (third-instar) and infected larvae. The arrow indicates a large plasmatocyte of the infected larvae, arrowheads point to the giant hemocytes and filariform structures. The fluorescence of not engulfed bacteria was quenched with trypan blue. Detection was done with a Zeiss Axioscope 2 MOT microscope. b FITC-labelled $E$. coli bacteria are engulfed by the 5C3-positive plasmatocytes. Staining was analyzed with an Olympus FV1000 confocal LSM microscope. Images are composed by merging four slides in the nucleus plane. Representative pictures were selected from 3 independent experiments, with 3 animals in each group. The scale bars represent 20 $\mu \mathrm{m}$.

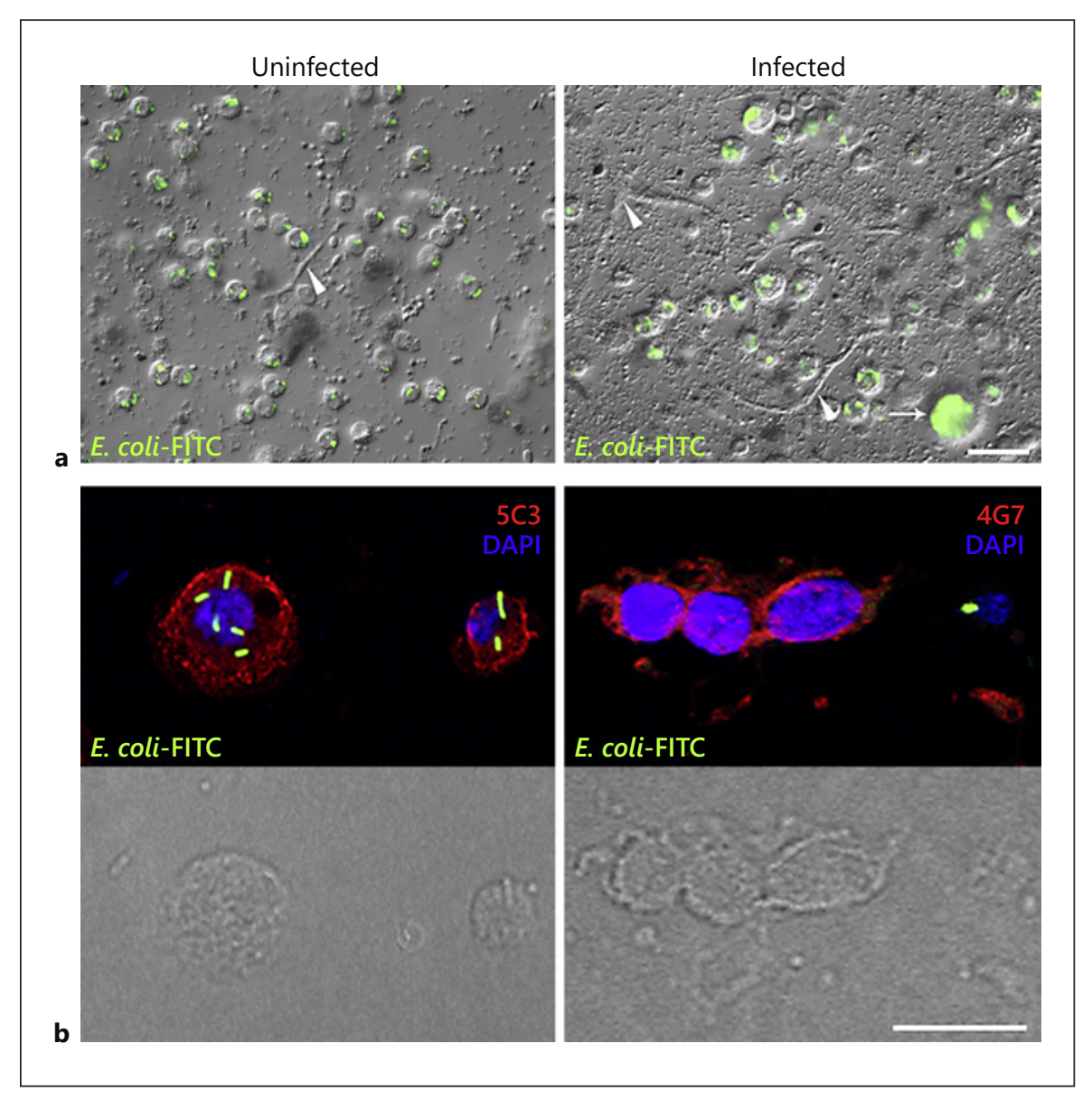

tometry. The DAPI florescence intensity revealed three nuclear subgroups in the naïve and four subgroups in the wasp-infected larvae (Fig. 8a, b), which correlates with the cell size. The nuclear fraction with the highest fluorescence intensity was characteristic for hemocytes of the infected larvae. When the DAPI fluorescence was correlated with the immune phenotype of isolated hemocytes, we found that the nuclei presenting higher fluorescence intensity were mostly those of the 4G7-positive giant hemocytes (Fig. 8c).

\section{Transmission Electron Microscopic Analysis of}

\section{Z. indianus Hemocytes}

Transmission electron microscopy analysis of fully developed MGHs revealed that these cells had a distinctly sponge-like overall appearance, as they possessed an elaborate system of canals and sinuses (Fig. 9a-g; online suppl. Fig. S5). The giant cell became polarized upon attachment to the parasite: it developed a basal and an apical layer. The basal layer was attached to the surface of the parasite, and the apical layer was in direct connection with the hemolymph. Getting closer to the surface of the parasite, the canal system gradually became narrow (Fig. 9a). The nuclei appeared to be randomly scattered in the cytoplasm and were not separated by a plasma membrane (Fig. 9b). Using a special fixative complemented with tannic acid [38], which allowed stronger staining of the plasma membrane, as opposed to intracellular membranes, we showed that this irregular system of canals and sinuses was extracellular and communicated with the hemolymph through openings on the outer surface of the cell (Fig. 9c; online suppl. Fig. S5). The thickappearing plasma membrane covered smaller and bigger areas of the cytoplasm, which were abundantly equipped with protruding thin microvilli and thin lamellae (Fig. 9d). The membranes of the intracellular organelles, like the Golgi apparatus, the endoplasmic reticulum, and mitochondrial membranes appeared much thinner than the plasma membrane (Fig. 9e, f, g). Interestingly, microtubules also appeared in this peripheral cytoplasm of the 
$24 \mathrm{~h}$
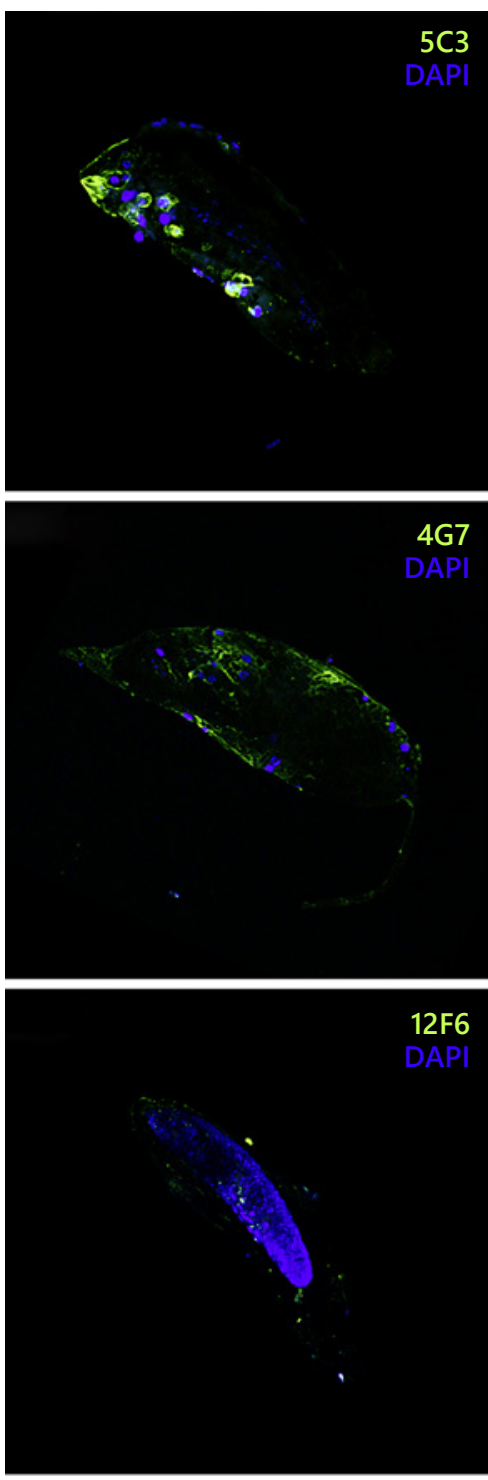

Control-
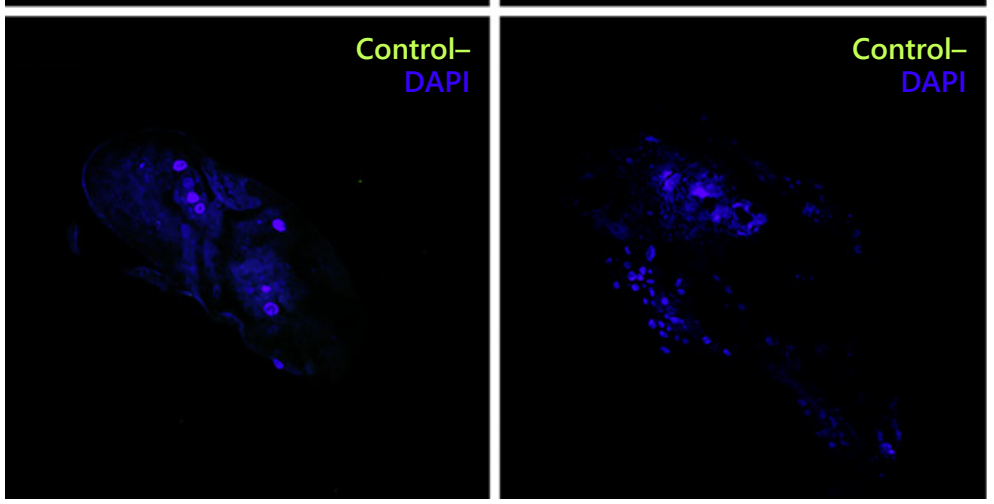

$48 \mathrm{~h}$
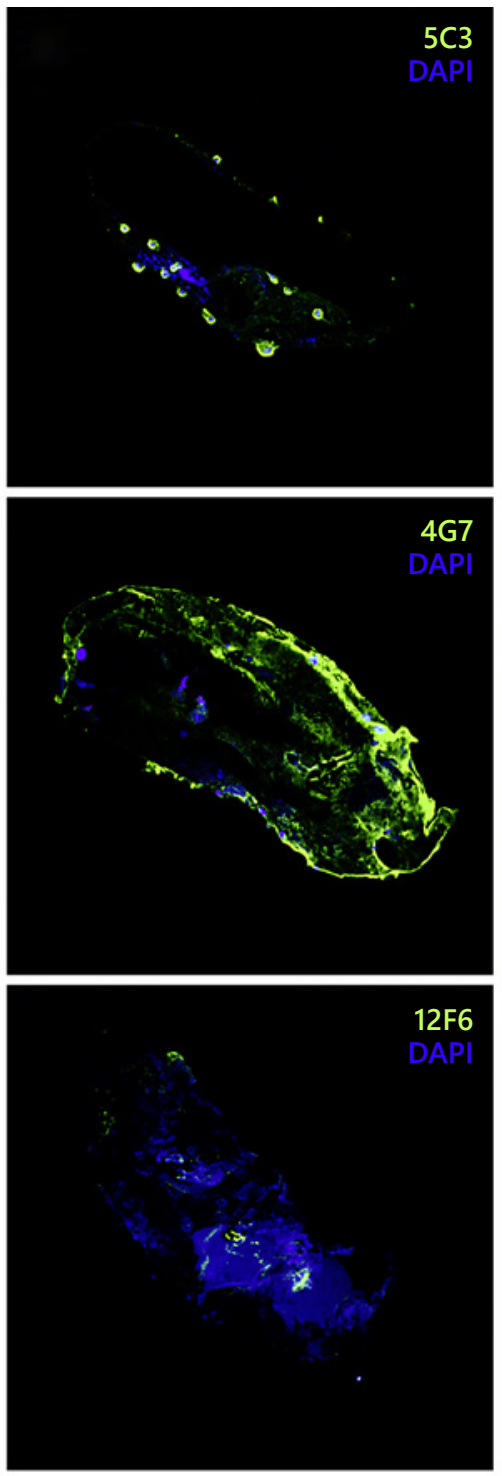

$12 \mathrm{~F} 6$
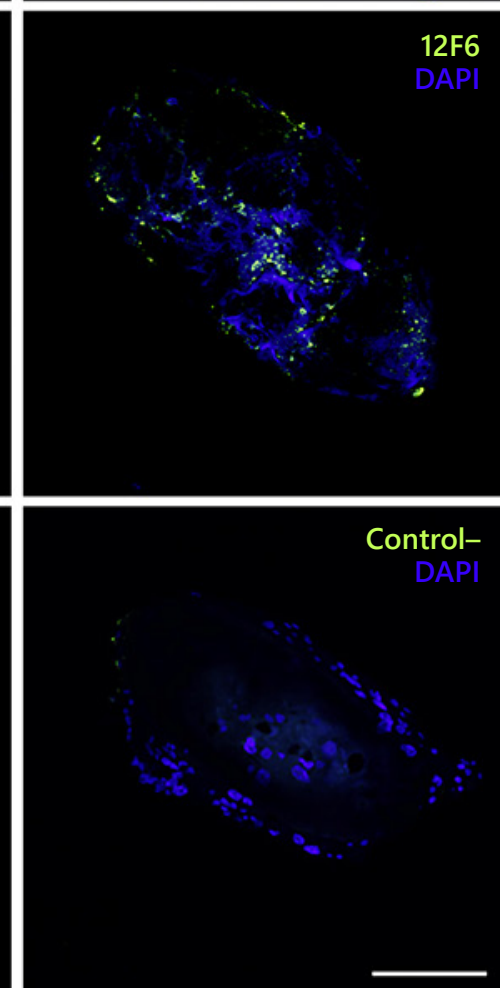

Fig. 5. Time-lapse analysis of the encapsulation reaction. L. victoriae parasitoids were isolated at different time points after infection of $Z$. indianus larvae, and indirect immunofluorescence staining was analyzed with an Olympus FV1000 confocal LSM microscope. The scale bar represents $200 \mu \mathrm{m}$. 


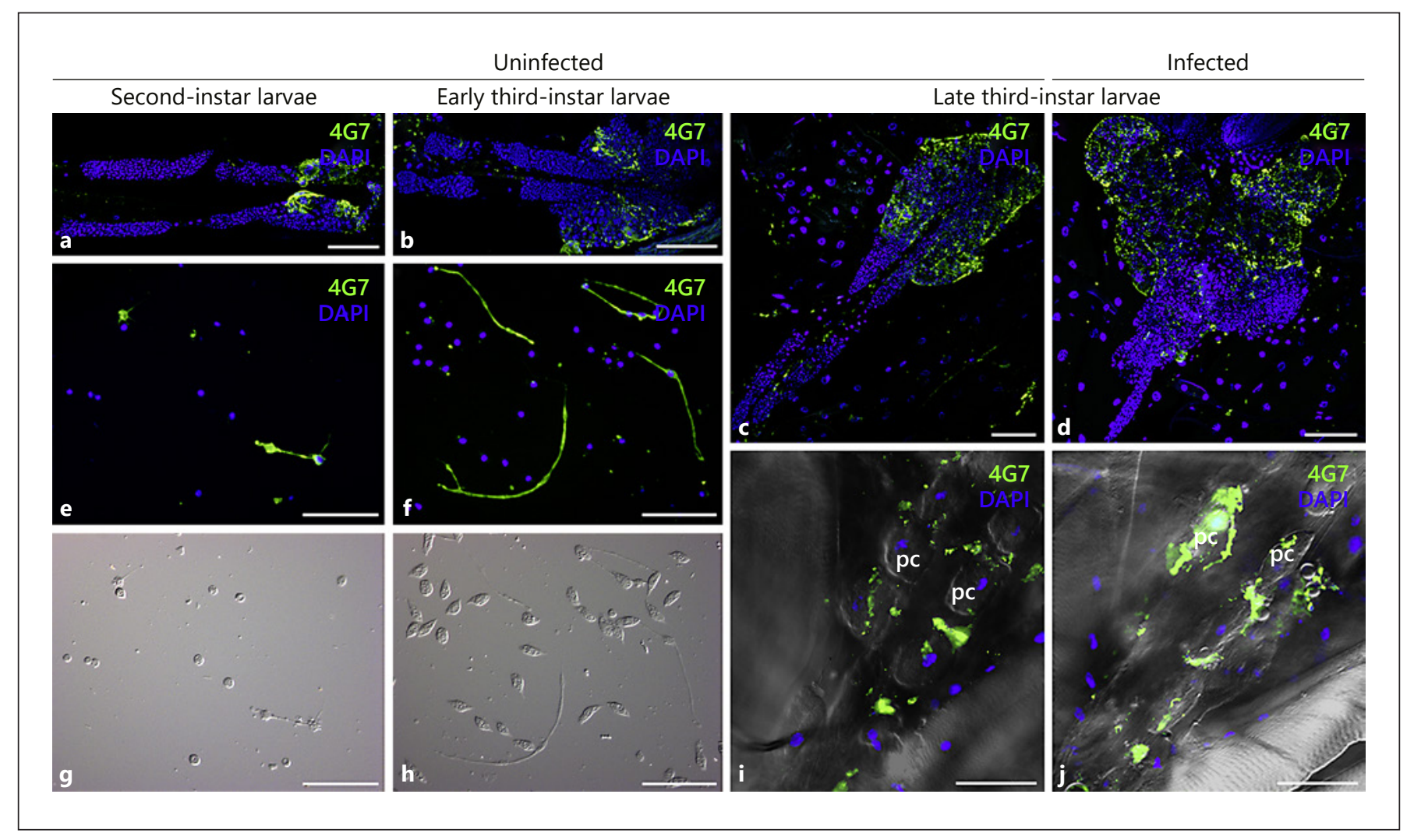

Fig. 6. Expression of the 4G7 antigen in the hematopoietic compartments of developing larvae. The lymph glands were isolated at different developmental stages from naïve (a-c) and infected (d) larvae. $\mathbf{e - h}$ Blood cells of naïve second-instar and early third-instar larvae are shown. Expression of the 4G7 giant cell-specific antigen was also detected near the dorsal vessel around the pericardial cells (pc) at the posterior region of uninfected (i) and infected larvae (j). Samples were reacted with the 4G7 and anti-mouse Alexa Fluor 488 antibodies. Staining was analyzed with an Olympus FV1000 confocal LSM microscope (a, b, c, and $\mathbf{d}$ ), or with an epifluorescence Zeiss Axioscope 2 MOT microscope $(\mathbf{e}-\mathbf{j})$. Scale bars represent $50 \mu \mathrm{m}$. giant cell (Fig. 9g), and multiform dense bodies with variable shape and size could also be observed (Fig. 9a, d). The irregular shape of the cytoplasmic islands, the thin microvilli and lamellae, made the plasma membrane extremely large, especially in the spongy region. When analyzing the ultrastructure of the giant cell localized on the parasitoid wasp, we observed that, in this case too, the canal system was wider at the periphery, while it became narrower when approaching the surface of the embedded parasite (Fig. 9a).

Plasmatocytes lack caverns, channels, and sinuses (fig. 9h, i; online suppl. Fig. S5); hence, these structures were characteristic exclusively for the giant hemocytes. Both types of plasmatocytes showed thin lamellar projections and were active in phagocytosis, engulfing microbes and cell debris (Fig. 9h, i).

\section{Discussion}

We were able to obtain new insights into the immunity of $Z$. indianus, an invasive species achieving a highly effective hemocyte-mediated protection against a large number of parasitoid wasp species [20,28]. Based on our data, obtained using blood cell type-specific monoclonal antibodies, functional assays, and morphological analysis, we identified three main hemocyte types in larvae and also in adult flies, both in naïve and infected animals: the giant hemocytes and their derivatives (4G7-positive cells and structures), the plasmatocytes (5C3-positive cells), and the crystal cells (12F6-positive cells). Previously, we already found that MGHs differentiate in the species of the ananassae subgroup of Drosophilidae in response to infection by parasitic wasps [6]. In comparison with the MGHs of species from the ananassae subgroup, the giant 

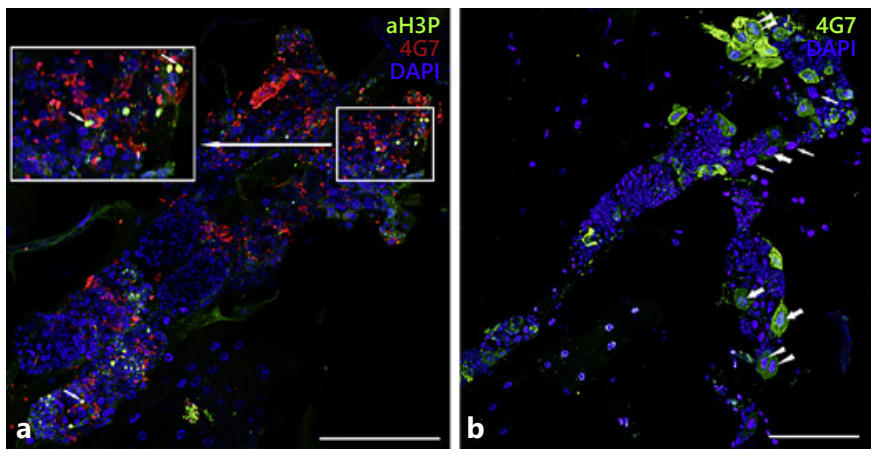

Fig. 7. Mitotic and binucleated cells in the lymph gland. a Analysis of the mitotic cells in the lymph gland $24 \mathrm{~h}$ after the infection, using anti-phospho-histone $\mathrm{H} 3$ and $4 \mathrm{G} 7$ antibodies. Arrows point to 4G7-positive cells (red) carrying the mitosis marker (green). b The lymph gland $48 \mathrm{~h}$ post-infection. Enlarged nuclei of 4G7-positive cells (thick arrows), nuclei of binucleated 4G7-positive cells (arrowheads), and enlarged nuclei of 4G7-negative cells (thin arrows) are indicated. Staining was analyzed with an Olympus FV1000 confocal LSM microscope. Scale bars represent $50 \mu \mathrm{m}$.

hemocytes of $Z$. indianus are also present in the uninfected animals. The morphology of these cells is more filariform and in general they are smaller when compared to the MGHs in the species of the ananassae subgroup. In response to wasp infection, not only giant cells differentiated, but large, plasmatocyte-like cells also appeared (Fig. 1e), which shared the functional characteristics of normal sized plasmatocytes when engulfing bacteria (Fig. 4).

Plasmatocytes in Z. indianus, similarly to other Drosophilids, are not only actively engulfing bacteria (Fig. 4) but are also involved in the encapsulation of the parasite (Fig. 5). The giant hemocytes are not phagocytic, but are involved in the encapsulation of the parasite egg and the larva. Nematocytes of $Z$. indianus were already shown to be present in the capsule formed around the parasitoid wasp eggs [20]. Using the PPO2-specific antibody, we observed a diffuse reaction on the parasitic egg, which could not be assigned to any cellular structure, but showed that a PPO2 ortholog could also be involved in the encapsulation reaction.

Anucleated cell fractions are likely derived from the giant hemocytes. Previously, we observed anucleated structures in $D$. ananassae and $D$. bipectinata [unpubl. data], and this phenomenon was also described in the hemocytes of $D$. falleni and $D$. phalerata [39]. We were now able to show that $Z$. indianus produces anucleated structures both in larvae and adults. The function of these an- ucleated structures is unknown, but a similar phenomenon was found in vertebrates, when the anucleated thrombocytes, which mediate blood clotting, were generated from the polyploid megakaryocytes [40]. This phenomenon appears to be highly similar to the possibly polyploid giant hemocytes and anucleated cell fractions of Drosophila species.

In D. melanogaster, the three blood cell compartments (i.e., the lymph gland, the sessile tissue, and the circulating blood cells, respectively) are involved in the differentiation of the encapsulating hemocytes, the lamellocytes $[5,6,17]$. Previously, we recognized that in D. ananassae the differentiation of the MGHs takes place outside of the lymph gland [22], and we now conclude that in Z. indianus, the lymph gland plays a pivotal role in the differentiation of the giant cells under both naïve and immuneinduced conditions, as 4G7-positive cells appear in the organ early in the development, and after immune induction the organ is swollen and releases the giant cells. It is not clear, however, how the multinucleated giant cells are formed in the lymph gland, nuclear division may contribute to their formation. After the burst of the organ, a strong rise in the number of the giant cells can be observed at the posterior end of the heart vessel.

We have observed that following wasp infection, the nuclei of the 4G7-positive cells and those of some large plasmatocytes in the circulation are enlarged (Fig. 1d, e). Nuclear enlargement was also observed $48 \mathrm{~h}$ after wasp infection in each of the 4G7-positive cells and some 4G7negative cells of the lymph gland (Fig. 7b). Moreover, the binucleated lymph gland cells were all 4G7 positive and carried enlarged nuclei. Multinucleation of giant cells may also occur outside the lymph gland by cell fusion (Fig. 3, online suppl. Movie 1 and 3).

As the immune induction results in enlarged nuclei in both, the encapsulating cells and in a subpopulation of phagocytic plasmatocytes, we have correlated the nuclear size with the DNA content by FACS analysis. We found that the nuclear size correlates with the DNA content (Fig. 8a, b). According to the DAPI fluorescence intensity, the nuclei of the uninfected hemocytes can be divided into three subgroups, while in case of the infected animals, four subgroups were detected (Fig. 8a, b). The subgroup possessing the highest DAPI fluorescence intensity, hence probably the highest ploidy level, was present only in the hemocytes of the infected larvae. These nuclei belong mostly to the terminally differentiated giant (4G7positive) hemocytes (Fig. 8c). Polyploidy occurs in highly differentiated cells in Drosophila. Cells of the adult rectal papillae are polyploid and undergo normal mitotic cycles 
Fig. 8. Fluorescence intensity of isolated nuclei obtained from circulating hemocytes of uninfected (a) and infected (b) larvae, as determined with a BD FACSJazz Cell Sorter. c The immune phenotype of the hemocytes from uninfected and infected larvae was correlated with the nuclear fluorescence intensity using the ImageJ program (http://imagej.nih.gov/ij/). Nuclear DNA was stained with DAPI. The error bars indicate the standard error of the mean. $p<0.001$.

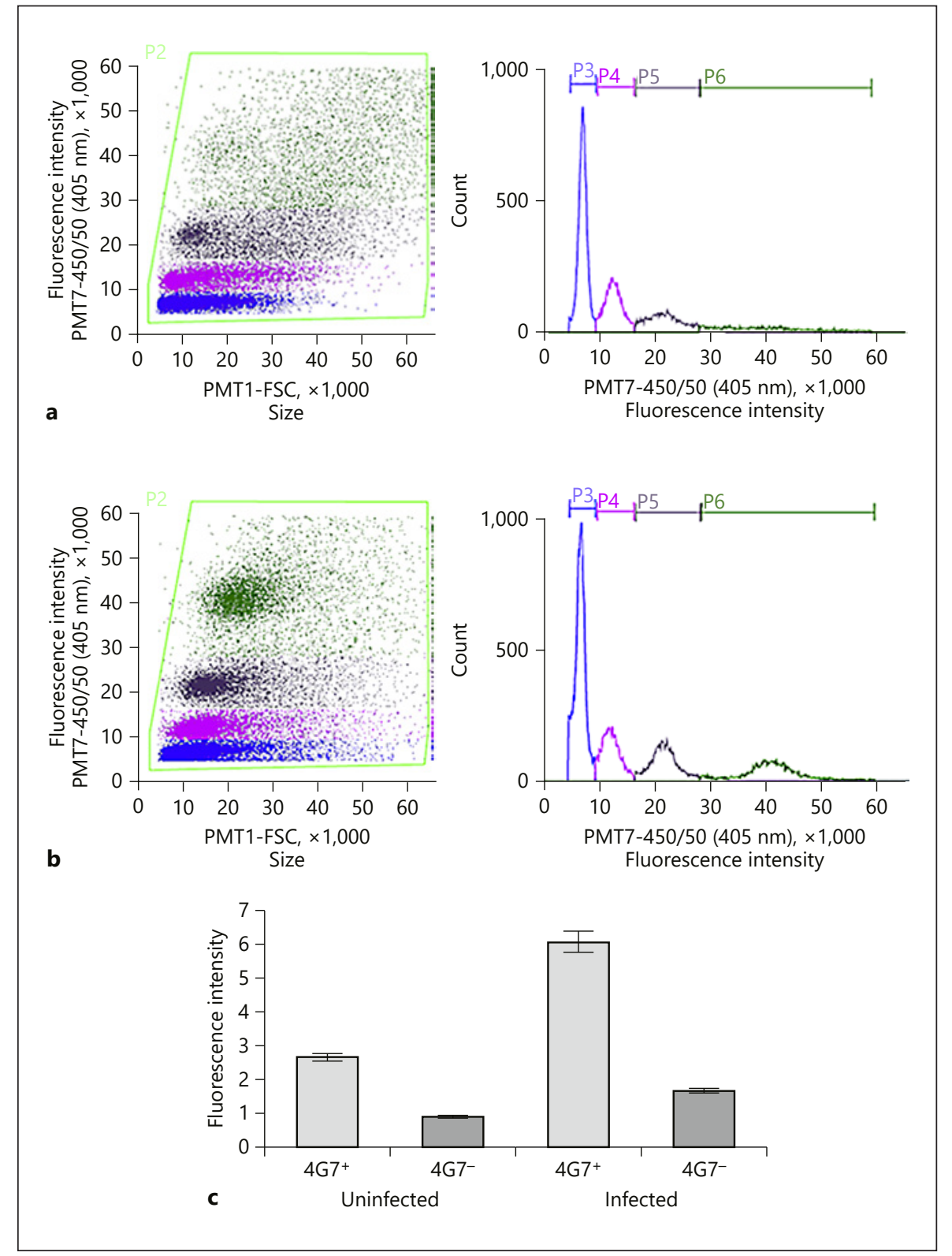

Fig. 9. Electron micrographs of the $Z$. indianus hemocytes. a Large portion of a giant cell. At the periphery, a loose, irregular network of electron lucent extracellular canals is present, which becomes denser when approaching the surface of the L. victoriae parasitoid (pt). The black areas are multiform dense bodies (mdb). An electron-dense layer $(\mathrm{dl})$ is firmly attached to the parasitoid. b Multiple nuclei $(\mathrm{n})$ in the giant cell (notice the lack of plasma membrane between the nuclei). c Communication pores between the environment and the extracellular network of canals at the periphery of a giant cell (arrows). d Large number of thinner or thicker lamellae (white arrows) and thin microvilli (black arrows) protrude into the canal system; multiform dense body with branching projection (black arrowhead). e The plasma membrane appears to be thick (black arrowhead), while internal membranes like that of transGolgi elements are thin (white arrowhead) due to the fixation with tannin. f Thick plasma membrane (black arrowhead) and a mitochondrion with thin membrane (white arrowhead). g Microtubules in the peripheral cytoplasm of the giant cell (black arrows). h Large plasmatocyte. i Small plasmatocyte. Both plasmatocytes are capable of performing phagocytosis; phagosomes (white arrows), nucleus (n), lamellar projections (black arrows). Hemocytes were isolated from $Z$. indianus larvae $72 \mathrm{~h}$ following the L. victoriae parasitoid infection.

(For figure see next page.) 

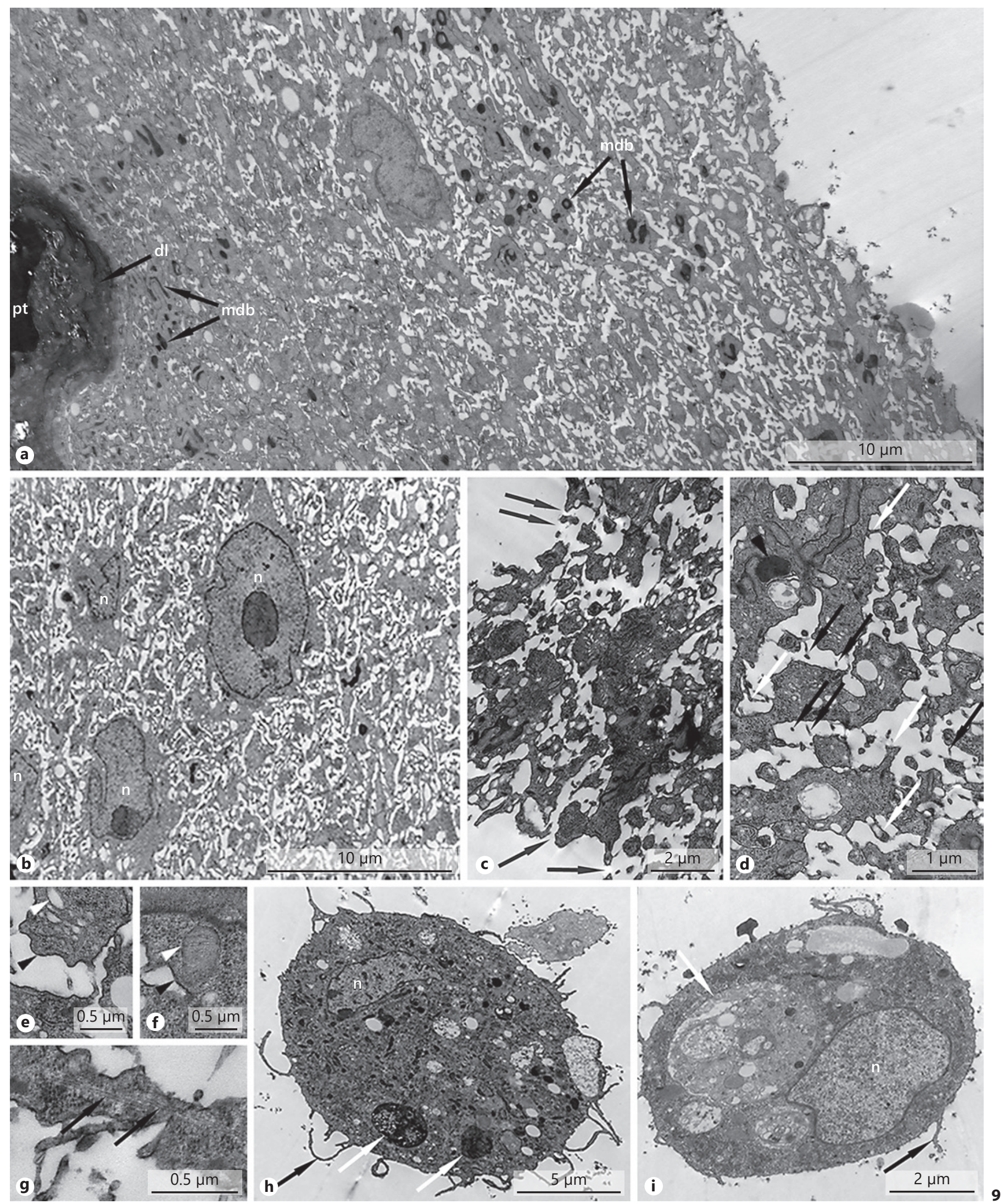

Genome Amplification during the

J Innate Immun 2020;12:257-272 269 
[41]. Moreover, the subperineurial glia of D. melanogaster larvae are polyploid, and it was shown that polyploidy is critical for the maintenance of the blood-brain barrier [42].

The MGHs of Drosophila are motile cells with filamentous projections, and they strongly resemble multinucleated giant cells found in mammalian foreign body-type granulomas, developed with fusion of macrophages. Polyploid macrophages having role in granuloma formation were also reported $[43,44]$. Since the mechanism and biological importance of macrophage fusion, polyploidization, are only partially understood, we anticipate that studies on MGHs may broaden our knowledge on the development, structure, and granuloma formation in general.

As the increased DNA content and multinucleation may provide a metabolic advantage for the giant hemocytes, we tested whether all of the nuclei were transcriptionally active or if there was a variation between the transcriptional activities, as observed in the multinucleated osteoclasts [37]. All the nuclei of the giant hemocytes were found to be transcriptionally active, suggesting that the multinucleation, combined with the endoreplication, provide a two-stage amplification of the genetic material within a single cell.

The electron microscopic analysis revealed that the giant hemocytes possess an elaborate canal system, which is lined with plasma membrane, creating a sponge-like structure, thereby providing an extremely large contact surface with the extracellular space. No matter how unusual it is, this structural arrangement must obviously serve an efficient way to isolate and kill the parasite. In finding connection of structure with function, we must recognize that the extracellular compartment has only a limited connection to the circulating hemolymph by surface pores on the overall boundary of the giant cell. This may allow the giant cell to create and control a large volume of extracellular fluid, which has a somewhat different composition than the overall hemolymph. Structurally this arrangement is advantageous in achieving high motility (microtubules are abundant in the spongy region) and flexibility for changing the shape, which is a major requirement for engulfing the parasite.

Our data indicate that the invasive $Z$. indianus possesses a well-organized and effective immune system, including a unique cell type in innate immunity, the MGH. Multinucleation, and amplification of the nuclear DNA, provide remarkable increase of the genetic material, hence permitting a high level of protein expression. Moreover, the particular cellular ultrastructure, allowing an extremely large contact area with the environment, enhances functional efficiency; thus, all these features may contribute to a highly efficient immune response.

\section{Acknowledgement}

We are grateful to Olga Kovalcsik, Anita Balázs, Mónika Ilyés, and Sarolta Pálfia for the technical help. Special thanks to Dr. Ferhan Ayaydin of Laboratory of Cellular Imaging, BRC, for 3D confocal picture reconstruction. We thank Prof. Todd Schlenke for $L$. victoriae, Bálint Z. Kacsoh for the Zaprionus indianus strains, Prof. Tina E. Trenczek for the 12F6 antibody and Dr. László Krenács for valuable discussions. We acknowledge the anonymous reviewers for their valuable suggestions and comments, which improved the quality of the manuscript. This research was supported by grants from the Hungarian National Science Foundation, NKFI K128762 (G.C.), GINOP-2.3.2-15-2016-00001 (I.A.), NKFI NN118207 (I.A.), NKFI K120142 (I.A.), GINOP-2.3.2-15-2016-00035 (É.K.), GINOP-2.3.2-15-2016-00032 (G.J.), PD127968 (I.K.), GINOP2.3.2-15-2016-00032 (P.V.), and the Szeged Scientists Academy Program of the Foundation for the Future of Biomedical Sciences in Szeged implemented with the support of the Ministry of Human Resources (TSZ:34232-3/2016/INTFIN).

\section{Statement of Ethics}

Animal experiments conform to internationally accepted standards and have been approved by the appropriate institutional review body (CS/I01/765/2018).

\section{Disclosure Statement}

The authors have no conflicts of interest to declare.

\section{Funding Sources}

NKFI K128762 grant (G.C.): antibodies, Western blot kits, publishing fee. GINOP-2.3.2-15-2016-00001 (I.A.): costs of insect stocks and culturing, charge of immunization, and hybridoma culturing. NKFI NN118207 (I.A.): costs of components required for the indirect immunofluorescence, salary. NKFI K120142 (I.A.): charges of the Alpha XDS-1T inverse microscope and the Nikon D5300 DSLR camera required for videomicroscopy. GINOP2.3.2-15-2016-00035 (É.K.): charges of the work with the Olympus FV1000 confocal LSM microscope, costs of laboratory equipment required for the work. GINOP-2.3.2-15-2016-00032 (GJ): costs for the electron microscopic analysis. PD127968 (I.K.) and GINOP-2.3.2-15-2016-00032 (P.V.): costs of the nuclear isolation work and confocal microscopy with Leica TCS SP5. Szeged Scientists Academy Program of the Foundation for the Future of Biomedical Sciences in Szeged implemented with the support of the Ministry of Human Resources (TSZ:34232-3/2016/INTFIN): providing undergraduate student (Bálint Soós) to help with the work. 


\section{Author Contributions}

Gyöngyi Cinege: experimental design; hemocyte clustering; analysis of the hemocyte role in the encapsulation reaction; determining the role of the hematopoietic compartments in the blood cell differentiation; Western blot analysis; insect stocks and culturing, preparation of the manuscript. Zita Lerner: phagocytosis tests; preparation of samples for electron microscopic analysis; timelapse movie of the giant cells; cell fusion analysis in the circulation; analysis of the lymph gland role in the giant cell differentiation. Lilla B. Magyar: fluorescence intensity measurements of blood cell nuclei, statistical analysis, imaging, time-lapse movie of hemocytes. Bálint Soós: analysis of the H3P mitotic cell marker in the circulating hemocytes; analysis of the hemocyte role in the encapsulation reaction. Renáta Tóth: cell and nuclear measurements.
Evva Kurucz: production of monoclonal antibodies and their clustering. Ildikó Kristó: isolation of cell nuclei from larval hemocytes; DAPI staining and FACS analysis. Péter Vilmos: investigation of transcriptional activity of blood cell nuclei. Gábor Juhász: electron microscopic analysis of hemocytes. Attila L. Kovács: sample preparation and electron microscopic analysis of hemocytes, contribution to manuscript preparation. Zoltán Hegedüs: analysis of the molecular mass of the hemocyte antigens; Zaprionus indianus genome sequence analysis for PPO2 orthologs. Christoph W. Sensen: discussing the results and contribution to manuscript preparation. István Andó: experimental design; production of monoclonal antibodies and their clustering; FACS analysis of blood cell nuclei; study of compartmental origin of the giant hemocytes; preparation of the manuscript.

\section{References}

1 Evans CJ, Hartenstein V, Banerjee U. Thicker than blood: conserved mechanisms in Drosophila and vertebrate hematopoiesis. Dev Cell. 2003 Nov;5(5):673-90.

2 Hoffmann JA. The immune response of Drosophila. Nature. 2003 Nov;426(6962):33-8.

3 Gilmore TD, Wolenski FS. NF- $\kappa$ B: where did it come from and why? Immunol Rev. 2012 Mar;246(1):14-35.

4 Rizki TM, Rizki RM. Properties of the larval hemocytes of Drosophila melanogaster. Experientia. 1980;36(10):1223-6.

5 Lanot R, Zachary D, Holder F, Meister M. Postembryonic hematopoiesis in Drosophila. Dev Biol. 2001 Feb;230(2):243-57.

6 Márkus R, Laurinyecz B, Kurucz E, Honti V, Bajusz I, Sipos B, et al. Sessile hemocytes as a hematopoietic compartment in Drosophila melanogaster. Proc Natl Acad Sci USA. 2009 Mar;106(12):4805-9.

7 Honti V, Csordás G, Kurucz É, Márkus R, Andó I. The cell-mediated immunity of Drosophila melanogaster: hemocyte lineages, immune compartments, microanatomy and regulation. Dev Comp Immunol. 2014 Jan;42(1): 47-56.

8 Rizki MT. Alterations in the hemocyte population of Drosophila melanogaster. J Morphol. 1957;100(3):437-58.

9 Carton Y, Bouletreau M, van Alphen JJ, van Lenteren JC. The Drosophila parasitic wasps. In: Ashburner M, Carson L, Thompson JN, editors. The Genetics and Biology of Drosophila. Volume 3. London, UK: Academic Press; 1986. pp. 347-94.

10 Russo J, Dupas S, Frey F, Carton Y, Brehelin $\mathrm{M}$. Insect immunity: early events in the encapsulation process of parasitoid (Leptopilina boulardi) eggs in resistant and susceptible strains of Drosophila. Parasitology. 1996 Jan; 112(Pt 1):135-42.

11 Williams MJ. Drosophila hemopoiesis and cellular immunity. J Immunol. 2007 Apr; 178(8):4711-6
12 Honti V, Kurucz E, Csordás G, Laurinyecz B, Márkus R, Andó I. In vivo detection of lamellocytes in Drosophila melanogaster. Immunol Lett. 2009 Sep;126(1-2):83-4.

13 Stofanko M, Kwon SY, Badenhorst P. Lineage tracing of lamellocytes demonstrates Drosophila macrophage plasticity. PLoS One. 2010 Nov;5(11):e14051.

14 Honti V, Csordás G, Márkus R, Kurucz E, Jankovics F, Andó I. Cell lineage tracing reveals the plasticity of the hemocyte lineages and of the hematopoietic compartments in Drosophila melanogaster. Mol Immunol. 2010 Jul;47(11-12):1997-2004.

15 Avet-Rochex A, Boyer K, Polesello C, Gobert $\mathrm{V}$, Osman D, Roch F, et al. An in vivo RNA interference screen identifies gene networks controlling Drosophila melanogaster blood cell homeostasis. BMC Dev Biol. 2010 Jun;10(1):65.

16 Makhijani K, Alexander B, Tanaka T, Rulifson E, Brückner K. The peripheral nervous system supports blood cell homing and survival in the Drosophila larva. Development. 2011 Dec;138(24):5379-91.

17 Anderl I, Vesala L, Ihalainen TO, Vanha-Aho LM, Andó I, Rämet M, et al. Transdifferentiation and proliferation in two distinct hemocyte lineages in Drosophila melanogaster larvae after wasp infection. PLoS Pathog. 2016 Jul;12(7):e1005746.

18 Eslin P, Doury G. The fly Drosophila subobscura: a natural case of innate immunity deficiency. Dev Comp Immunol. 2006;30(11): 977-83.

19 Salazar-Jaramillo L, Paspati A, van de Zande L, Vermeulen CJ, Schwander T, Wertheim B. Evolution of a cellular immune response in Drosophila: a phenotypic and genomic comparative analysis. Genome Biol Evol. 2014 Feb;6(2):273-89.

20 Kacsoh BZ, Bozler J, Schlenke TA. A role for nematocytes in the cellular immune response of the drosophilid Zaprionus indianus. Parasitology. 2014 Apr;141(5):697-715.
21 Havard S, Doury G, Ravallec M, Brehélin M, Prévost G, Eslin P. Structural and functional characterization of pseudopodocyte, a shaggy immune cell produced by two Drosophila species of the obscura group. Dev Comp Immunol. 2012 Feb;36(2):323-31.

22 Márkus R, Lerner Z, Honti V, Csordás G, Zsámboki J, Cinege G, et al. Multinucleated giant hemocytes are effector cells in cell-mediated immune responses of Drosophila. J Innate Immun. 2015;7(4):340-53.

23 Adams DO. The granulomatous inflammatory response. A review. Am J Pathol. 1976 Jul;84(1):164-92.

24 Schmitz HJ, Valente VL, Hofmann PR. Taxonomic survey of Drosophilidae (Diptera) from mangrove forests of Santa Catarina Island, Southern Brazil. Neotrop Entomol. 2007 Jan-Feb;36(1):53-64.

25 Yassin A, Araripe LO, Capy P, Da Lage JL, Klaczko LB, Maisonhaute C, et al. Grafting the molecular phylogenetic tree with morphological branches to reconstruct the evolutionary history of the genus Zaprionus (Diptera: drosophilidae). Mol Phylogenet Evol. 2008a Jun;47(3):903-15.

26 Vilela CR. Is Zaprionus indianus Gupta (1970 Diptera, Drosophilidae) currently colonizing the Neotropical region? Drosoph Inf Serv. 1999;82:37-9.

27 Commar LS, Galego LG, Ceron CR, Carareto CM. Taxonomic and evolutionary analysis of Zaprionus indianus and its colonization of Palearctic and Neotropical regions. Genet Mol Biol. 2012 Apr;35(2):395-406.

28 Kremmer L, David J, Borowiec N, Thaon M, Ris N, Poirié M, et al. The African fig fly $\mathrm{Za}$ prionus indianus: a new invasive pest in France. Bull Insectol. 2017;70(1):57-62.

29 Khanna R, Mohanty S. Whole genome sequence resource of Indian Zaprionus indianus. Mol Ecol Resour. 2017 May;17(3):55764. 
30 Kurucz E, Váczi B, Márkus R, Laurinyecz B, Vilmos P, Zsámboki J, et al. Definition of Drosophila hemocyte subsets by cell-type specific antigens. Acta Biol Hung. 2007;58 Suppl:95-111.

31 Trenczek T, Bennich H. Characterization of haemocytes of Hyalophora cecropia by monoclonal antibodies. Verh Dtsch Zool Ges. 1992;85:216.

32 Trenczek T, Scholz FR, Poppe R, Franke S, Gateff E. Characterization of a hemocyte component typical of granular cells of Hyalophora cecropia pupae and crystal cells of Drosophila melanogaster but also present in garland cells of late Drosophila embryo. Proceedings DGfI, Jena. 1999.

33 Vilmos P, Nagy I, Kurucz E, Hultmark D, Gateff E, Andó I. A rapid rosetting method for separation of hemocyte sub-populations of Drosophila melanogaster. Dev Comp Immunol. 2004 May;28(6):555-63.
34 Williams MJ, Andó I, Hultmark D. Drosophila melanogaster Rac2 is necessary for a proper cellular immune response. Genes Cells. 2005 Aug;10(8):813-23.

35 Krause SA, Loupart ML, Vass S, Schoenfelder S, Harrison S, Heck MM. Loss of cell cycle checkpoint control in Drosophila Rfc4 mutants. Mol Cell Biol. 2001 Aug;21(15):515668.

36 Reynolds ES. The use of lead citrate at high $\mathrm{pH}$ as an electron-opaque stain in electron microscopy. J Cell Biol. 1963 Apr;17(1):208-12.

37 Youn MY, Takada I, Imai Y, Yasuda H, Kato $S$. Transcriptionally active nuclei are selective in mature multinucleated osteoclasts. Genes Cells. 2010 Oct;15(10):1025-35.

38 Wagner RC. The effect of tannic acid on electron images of capillary endothelial cell membranes. J Ultrastruct Res. 1976 Nov;57(2): 132-9.
39 Bozler J, Kacsoh BZ, Bosco G. Nematocytes: discovery and characterization of a novel anculeate hemocyte in Drosophila falleni and Drosophila phalerata. PLoS One. 2017 Nov; 12(11): 0188133.

40 Ravid K, Lu J, Zimmet JM, Jones MR. Roads to polyploidy: the megakaryocyte example. J Cell Physiol. 2002 Jan;190(1):7-20.

41 Fox DT, Gall JG, Spradling AC. Error-prone polyploid mitosis during normal Drosophila development. Genes Dev. 2010 Oct;24(20): 2294-302.

42 Unhavaithaya Y, Orr-Weaver TL. Polyploidization of glia in neural development links tissue growth to blood-brain barrier integrity. Genes Dev. 2012 Jan;26(1):31-6.

43 Herrtwich L, Nanda I, Evangelou K, Nikolova T, Horn V, Sagar, et al. DNA damage signaling instructs polyploid macrophage fate in granulomas. Cell. 2016 Nov; 167(5):12641280.e18.

44 Horn V, Triantafyllopoulou A. DNA damage signaling and polyploid macrophages in chronic inflammation. Curr Opin Immunol. 2018 Feb;50:55-63. 